\title{
Relation Between Horizontal Ventilation Velocity and Backlayering Distance in Large Closed Car Parks
}

\author{
NELE TILLEY ${ }^{1,2}$ and BART MERCI ${ }^{1,3}$ \\ ${ }^{1}$ Department of Flow, Heat and Combustion Mechanics \\ Ghent University - UGent \\ Sint-Pietersnieuwstraat 41, B-9000 Ghent, Belgium (Nele.Tilley@UGent.be) \\ ${ }^{2}$ Ph.D. grant of the Institute for the Promotion of Innovation by Science and Technology in \\ Flanders (IWT-Vlaanderen). \\ ${ }^{3}$ Postdoctoral Fellow of the Fund of Scientific Research - Flanders (Belgium) (FWO-Vlaanderen)
}

\begin{abstract}
Due to the ceiling jet phenomenon, smoke above a fire source has a natural tendency to spread under the ceiling in all directions, until a barrier is reached. The present study focuses on smoke control, rather than smoke clearance, in large closed car parks. A particular situation is that the ceiling height is much lower than the horizontal car park dimensions. Also, flame heights can be in the same order of magnitude as the ceiling height, so that flames can penetrate into the smoke layer under the ceiling near the fire source. Smoke control in case of fire in large car parks can be established by horizontal mechanical ventilation. A 'critical ventilation velocity' exists, for which no smoke backlayering occurs, i.e. the car park is maintained smoke-free at one side of the fire source. In many cases, however, backlayering can be allowed to a certain distance. We analyse the results from a large series of CFD-simulations, used as numerical experiments, and illustrate that there is a relation between the horizontal ventilation velocity and the backlayering distance. The backlayering distance varies linearly with the difference between the critical ventilation velocity and the actual ventilation velocity of the incoming fresh air. We perform a parameter study with variation of heat release rate per unit area, fire source area, car park width and car park height. We show that the coefficient in the mentioned linear relationship is independent of the fire source area, the car park height and the car park width, but increases with decreasing heat release rate per unit area. We compare the results for the critical ventilation velocity in car parks to results obtained in tunnel fires. We confirm the observations that the critical ventilation velocity increases with fire source area and heat release rate per unit area, as well as a small influence of the car park width. We observe an increase of the critical ventilation velocity with increasing car park height. Finally, we point out that care must be taken when a smoke control system design is based on volume flow rates, calculated from cold inlet flow velocities, as differences between extraction velocities and incoming air velocities can be substantial.
\end{abstract}

KEYWORDS: large closed car parks, smoke management, horizontal mechanical ventilation, backlayering, CFD, performance-based design, modelling, fluid dynamics

\section{NOMENCLATURE LISTING}

\begin{tabular}{llll}
$A$ & area $\left(\mathrm{m}^{2}\right)$ & $v$ & velocity $(\mathrm{m} / \mathrm{s})$ \\
$a$ & slope in linear relation $(\mathrm{s})$ & $w$ & width $(\mathrm{m})$ \\
$c_{p}$ & heat capacity $(\mathrm{kJ} /(\mathrm{kg} \cdot \mathrm{K}))$ & $\rho$ & density $\left(\mathrm{kg} / \mathrm{m}^{3}\right)$ \\
$d$ & backlayering distance $(\mathrm{m})$ & \multicolumn{2}{l}{} \\
$D$ & diameter of fire source $(\mathrm{m})$ & \multicolumn{2}{c}{ Subscripts } \\
$g$ & gravity acceleration $\left(\mathrm{m} / \mathrm{s}^{2}\right)$ & in & inlet \\
$h$ & ceiling height $(\mathrm{m})$ & out & outlet \\
$l$ & length $(\mathrm{m})$ & $F$ & fire/flame \\
$\dot{q}^{\prime \prime}$ & heat release rate per unit area $\left(\mathrm{kW} / \mathrm{m}^{2}\right)$ & 0 & ambient conditions \\
$\dot{Q}$ & heat release rate $(\mathrm{kW})$ & $c$ & convective \\
$\dot{m}$ & mass flow rate $(\mathrm{kg} / \mathrm{s})$ & $c r$ & critical \\
$T$ & temperature $(\mathrm{K})$ & &
\end{tabular}




\section{INTRODUCTION}

In the context of performance-based fire safety engineering, smoke control, by means of horizontal mechanical ventilation, can be applied in large closed car parks. This can be done at the level of 'smoke clearance' or at the level of limiting smoke movement to certain car park regions. We consider the latter option. Combination with sprinkling is possible and smoke control can be supported by local impulse ventilation fans. We, however, only consider stand-alone global horizontal mechanical ventilation by extraction at one side of a characteristic part of a large closed car park.

Though the comparison is not entirely correct [1], large closed car parks can, in a certain sense, be considered as tunnels with a very large width to height ratio. In tunnels, it is common practice not to allow any smoke backlayering (e.g. Beard and Carvel [2]), i.e. smoke should not move in the direction, opposite to the ventilation direction. The minimum required ventilation velocity is called the 'critical velocity' $v_{c r}$. Chow argues that car parks are too complex for ventilation to be characterized by a single quantity [1]. Still, it is interesting to consider results for critical ventilation velocities in tunnels for comparison purposes to our results. To give an example: in [3] it is discussed that $v_{c r}$ increases proportionally with the one-third power of heat release rate (HRR) up to a certain value of the HRR, above which $v_{c r}$ becomes independent of the HRR. We illustrate that the dependence on the fire source area, which was in fact not studied by Wu and Bakar [3], rather follows a one-fifth power law. An increase of $v_{c r}$ with increasing HRR per unit area is confirmed, but we do not observe a threshold value in our parameter range (see below).

One possible objective of performance-based fire safety design in car parks is for firemen to be able to extinguish the car fire. Therefore, they need to be able to approach the fire to a distance of about 10 to 15 meters. Such a distance appears in standards in different countries (e.g. [4,5]). This implies that a certain degree of backlayering is allowed. Thus, the required ventilation velocity will be lower than the critical velocity for which no backlayering occurs. Below, we try to quantify this.

Indeed, in the present study, we analyse the results of a large number of Computational Fluid Dynamics simulations (CFD). In a sense, we use the CFD results as numerical experiments. We use NIST's Fire Dynamics Simulator, version 4.0.7 [6]. A complete description of the numerical set-up is provided below.

The objectives of the study are twofold. First, we analyse the relation between critical ventilation velocity and a number of parameters. The following parameters are varied:

- fire source area,

- heat release rate per unit area,

- car park ceiling height,

- car park width.

The second objective is to construct a relation between the backlayering distance $d$ and the difference of the actually applied ventilation velocity and $v_{c r}$ for the studied configurations.

We also briefly discuss the possible danger in designing and testing smoke control systems, based on 'cold conditions'.

\section{NUMERICAL SET-UP}

Figure 1 shows the geometry. In the basic configuration, the car park dimensions are:

- $\quad$ width $w=16 \mathrm{~m}$,

- length $l=32 \mathrm{~m}$,

- height $h=2.4 \mathrm{~m}$,

- fire source area $A_{F}=5 \mathrm{~m} \times 5.2 \mathrm{~m}$,

- $\quad$ convective heat release rate per unit area (HRRPUA) $\dot{q}_{c}^{\prime \prime}=192 \mathrm{~kW} / \mathrm{m}^{2}$. 
This corresponds to $\dot{Q}_{c}=5 \mathrm{MW}$, a value in line with burning cars in the experimental data of [7] under the assumption that the convective HRR is about $80 \%$ of the total HRR.
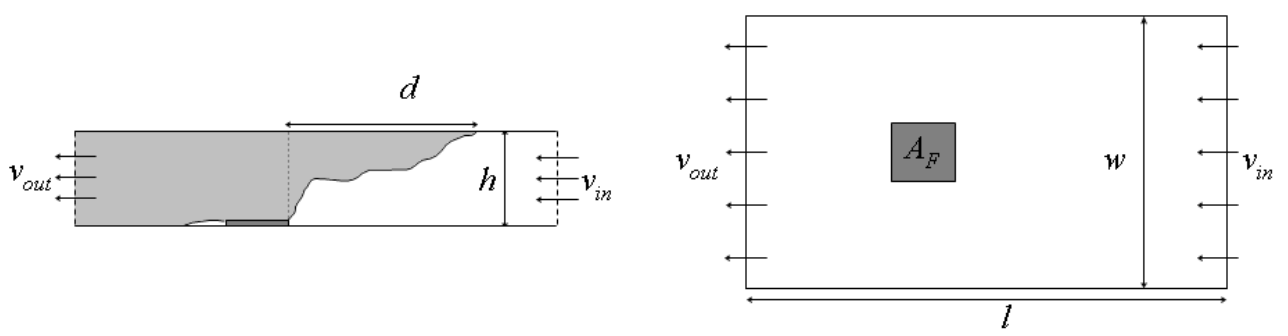

Fig. 1. Configuration of car park: side view (left) and top view (right).

Note that the floor surface area $16 \mathrm{~m} \times 32 \mathrm{~m}=512 \mathrm{~m}^{2}$ can hardly be called a large car park. However, the configuration under study must be regarded as a characteristic part of a larger car park. Indeed, as outlet boundary condition, a uniform velocity is imposed. This corresponds to a certain exhaust ventilation volume flow rate, assuming that the ventilation system is at sufficiently large distance from the fire source. Indeed, we do not focus on local flow effects due to the presence of ventilation equipment close to the fire source. Thus, the downstream distance from the fire source can be much larger than what is simulated here. The mass flow rate will basically remain the same up to the ventilation fans and the primary effect will be a variation in pressure. We do not include this in the simulations, so as not to unnecessarily increase computing times. Similarly, the inlet boundary of the computational domain is set at a distance of $17 \mathrm{~m}$ from the fire source, so that a backlayering distance of $15 \mathrm{~m}$ can be studied. Inclusion of a larger distance upstream of the fire source would again lead to longer computing times, without additional interesting information in the simulations.

As mentioned, the CFD simulations are carried out with FDS, version 4.0.7. The turbulence model is a standard Smagorinsky LES model (Large Eddy Simulations), with $C_{d}=0.20$. Uncertainty due to radiation modelling is eliminated by using the convective HRR as energy input and applying adiabatic boundary conditions at all walls. The default mixture fraction combustion model is used, thus relying on the assumption that the combustion process is mixture-controlled. Propane is used as surrogate fuel for the complex gases that are in reality released due to pyrolysis of combustible materials in real cars. For the physical smoke movement, this is justified, as the primary input for the movement is the (thermal) energy, not the chemical composition of the smoke. Smoke production is modelled by means of conversion of a fixed fraction of consumed fuel mass into smoke particulate. This 'soot yield' is set to 0.22 , a reasonable value for a car fire, according to [7].

The grid cell dimensions are: $20 \mathrm{~cm}$ in both horizontal directions, and $10 \mathrm{~cm}$ in height. The basic configuration car park contains 307200 cells. When the dimensions of the car park are varied in the simulations, the grid cells' dimensions are kept unchanged, so that the total number of cells varies. A grid refinement study revealed that the results, presented here, do not strongly depend on the grid size. However, it must be emphasized that, in principle, for high quality LES calculations, the grid size dimensions must be in the order of $5 \mathrm{~cm}$ or less $[8,9]$. Still, this is not crucial in the present study, as the effect on the relationship between ventilation velocities and backlayering distances is not very sensitive to the flow details and because intrinsic numerical dissipation in the flow solver also partly masks possible sensitivity of the results to grid size.

More than 130 simulations were carried out, in which four parameters were varied, independently of each other. Table 1 provides an overview of the values in the configurations under study. The values in bold refer to the basic configuration. 
Table 1. Simulated values of the four parameters. Values in bold: basic configuration.

\begin{tabular}{lccccccc}
\hline $\boldsymbol{A}_{\boldsymbol{F}}\left(\mathbf{m}^{\mathbf{2}}\right)$ & 1 & 4.8 & 10.2 & 15.2 & $\mathbf{2 6}$ & & \\
\hline \hline$\dot{\boldsymbol{q}}^{\prime \prime}\left(\mathbf{k W} / \mathbf{m}^{\mathbf{2}}\right)$ & 50 & 100 & $\mathbf{1 9 2}$ & 320 & 500 & 1000 & 1500 \\
\hline \hline $\boldsymbol{h}(\mathbf{m})$ & 1.8 & 2.0 & 2.2 & $\mathbf{2 . 4}$ & 2.6 & 3.0 & \\
\hline \hline $\boldsymbol{w}(\mathbf{m})$ & 12 & $\mathbf{1 6}$ & 20 & 24 & 28 & 32 & \\
\hline
\end{tabular}

As mentioned, a uniform extraction velocity $v_{\text {out }}$ is imposed over the entire outlet area. The inlet area is defined as 'open'. The fire source is set flush with the floor. The backlayering distance $d$ is defined as depicted in Fig. 1.

\section{VENTILATION VELOCITIES}

In tunnel applications, it is common practice to determine the critical velocity $v_{c r}$ at the inlet, i.e. based on the inflowing air stream $v_{\text {in }}$ (Fig. 1). We present the results in terms of inlet ventilation velocities as obtained in FDS and discuss the implications at the outlet boundary afterwards. This is important, since horizontal mechanical ventilation is typically applied in practice by extraction of smoke.

Before discussing the results, it is instructive to summarise the most important relationships from $\mathrm{Wu}$ and Bakar [3]. They analyse the results in terms of

$$
Q^{*}=\frac{\dot{Q}}{\rho_{0} c_{p} T_{0} \sqrt{g \bar{H}^{5}}} \quad \text { and } \quad V^{*}=\frac{V}{\sqrt{g \bar{H}}} \text {, }
$$

with the hydraulic tunnel height $\bar{H}$ defined as:

$$
\bar{H}=\frac{4 \cdot w \cdot h}{2 w+2 h}=2 \frac{w \cdot h}{w+h} .
$$

The formula in [3] for $v_{c r}$ in tunnels reads:

$$
\begin{aligned}
& v_{c r} \propto Q^{* 1 / 3} \cdot \bar{H}^{1 / 2} \propto \dot{q}_{c}^{, 1 / 3} A_{F}^{1 / 3} h^{-1 / 3}\left(1+\frac{h}{w}\right)^{1 / 3}, \quad Q^{*}<0.2 \\
& v_{c r} \propto h^{1 / 2}\left(1+\frac{h}{w}\right)^{-1 / 2}, \quad Q^{*}>0.2
\end{aligned}
$$

We investigate below whether these findings are reproduced. It is already interesting to note that only one fire source area was used in [3]. 
As mentioned in the introduction, we also investigate the relationship between the backlayering distance $d$ and the actually applied ventilation velocity $v_{i n}$. We illustrate below that there is an essentially linear relationship with the difference between $v_{c r}$ and $v_{i n}$, at least for the relevant backlayering distances:

$d=a\left(v_{c r}-v_{i n}\right), \quad 0 m<d<15 m$.

\section{IMPACT OF DIFFERENT PARAMETERS ON VENTILATION VELOCITY}

In the discussion of the results, only one parameter is varied at a time. The other values have been reported in bold in Table 1, corresponding to the basic configuration.

\section{Influence of fire source area}

As $\dot{q}_{c}^{\prime \prime}$ is kept constant, $\dot{Q}_{c}$ increases as $A_{F}$ increases. Figure 2 (left) reveals that the required inlet ventilation velocity $v_{i n}$ to guarantee a certain backlayering distance $d$, also increases with increasing $A_{F}$. It appears that the HRR threshold above which $v_{c r}$ does not increase any more with HRR, as reported in [3], has not (yet) been reached here. The dependence obeys a one-fifth power, rather than the one-third power in Eq. 3:

$\nu_{c r} \propto A_{F}^{0.2}$

The backlayering distance clearly increases as $v_{\text {in }}$ decreases, because the inertial forces due to forced ventilation become smaller, compared to the buoyancy forces in the plume (ceiling jet phenomenon). The right part of Fig. 2 reveals the practically linear relationship, quantified as Eq. 4. The value of the coefficient is practically independent of $A_{F}$ :

$a \approx 38 \mathrm{~s}$.
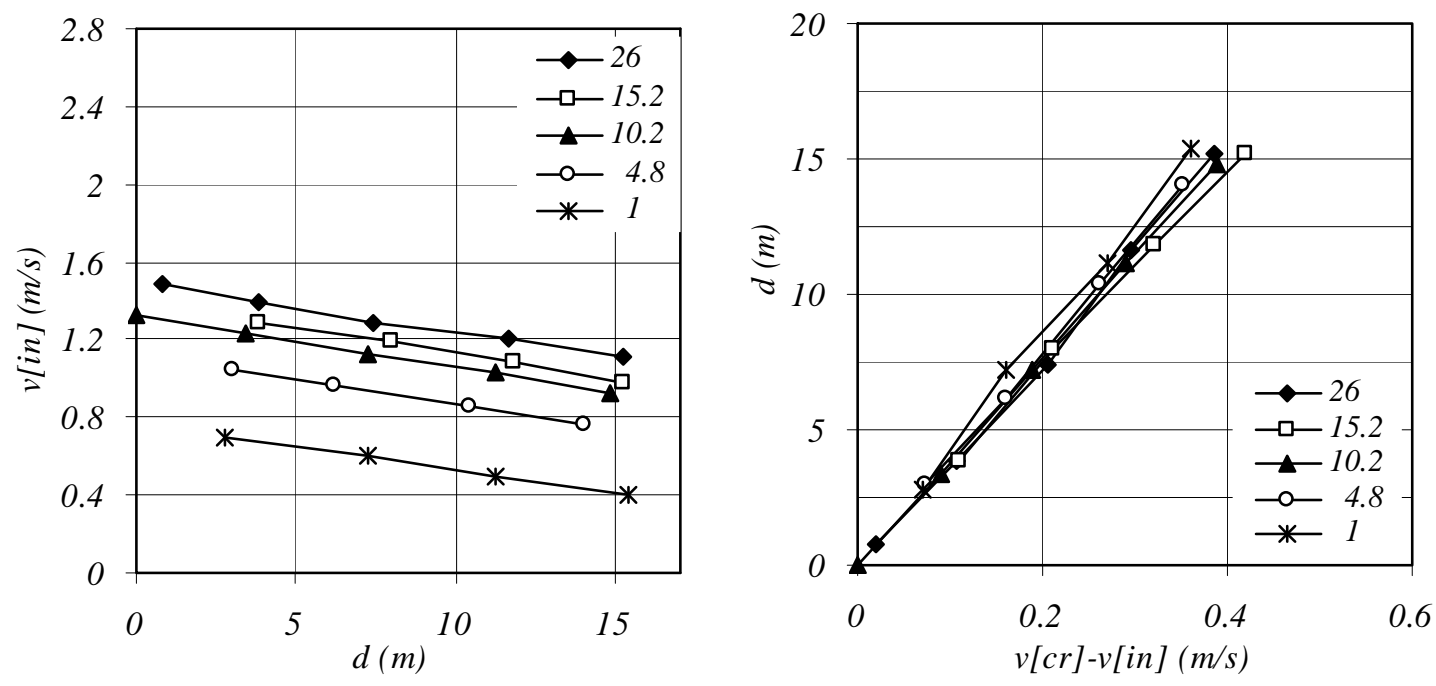

Fig. 2. Values of $v_{i n}$ and $d$ (left) and $d$ as function of $\left(v_{c r}-v_{i n}\right)$ (right) for different $A_{F}\left(\mathrm{~m}^{2}\right)$ values. 


\section{Influence of heat release rate per unit area}

As $A_{F}$ is constant, $\dot{Q}_{c}$ increases with increasing $\dot{q}_{c}^{\prime \prime}$. Figure 3 (left) reveals that $v_{i n}$ also increases. We do not observe a threshold value for the HRRs considered. The relation we find is:

$v_{c r} \propto \dot{q}_{c}^{\prime \prime 2.28}$

The right part of Fig. 3 clearly shows that $a$ depends on $\dot{q}_{c}^{\prime}$. We find a one-fifth power law dependence:

$a=111 \dot{q}_{c}^{,-0.2}(a$ in s).
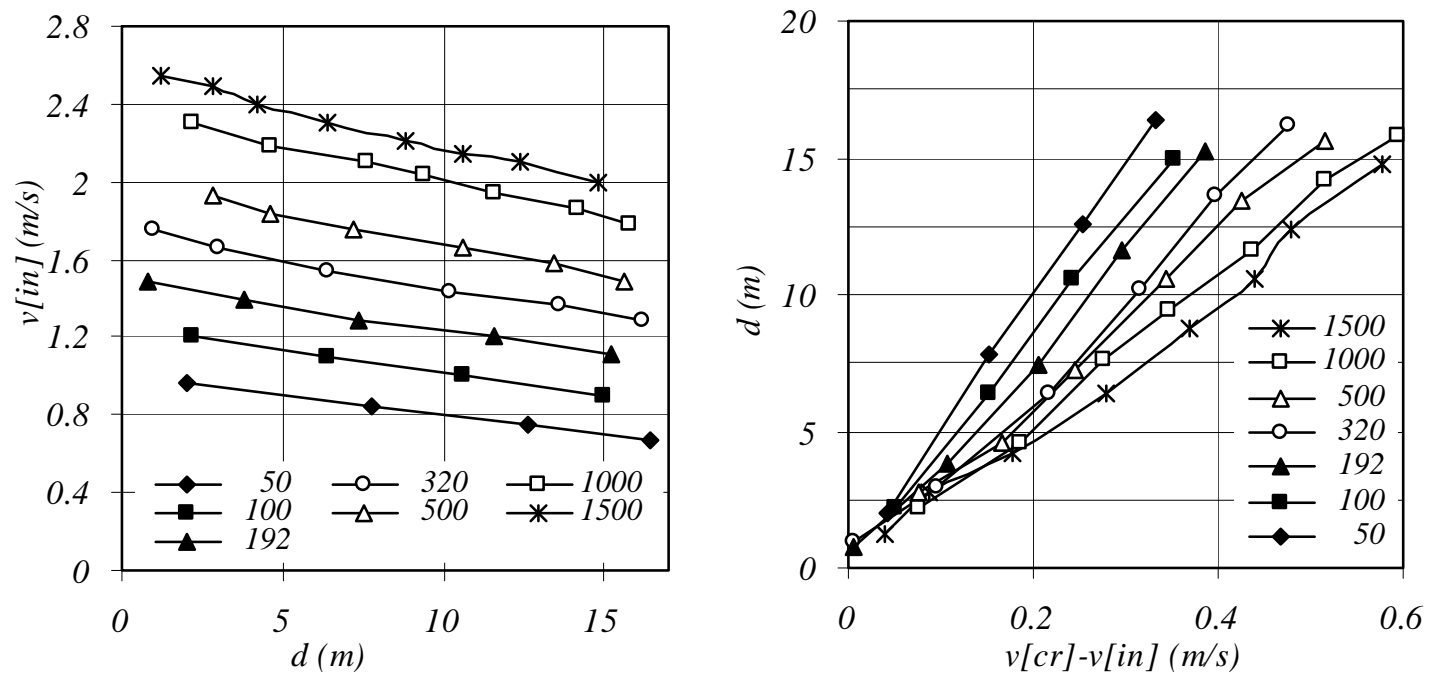

Fig. 3. Values of $v_{i n}$ and $d$ (left) and $d$ as function of $\left(v_{c r}-v_{i n}\right)$ (right) for different $\dot{q}_{c}^{\prime \prime}\left(\mathrm{kW} / \mathrm{m}^{2}\right)$ values.

It might seem counter-intuitive that the slope decreases as the HRR per unit area increases, implying that the backlayering distance increases less rapidly with decreasing incoming air ventilation velocity. Note, however, that the absolute values of $d$ increase for constant $v_{i n}$ value.

We also mention that the flame height is in the same order as the car park height. Indeed, Heskestad's correlation [10] yields the following estimate for the flame height for $\dot{q}_{c}^{\prime \prime}=192 \mathrm{~kW} / \mathrm{m}^{2}$ :

$l_{F}=0.23 \cdot \dot{Q}^{0.4}-1.02 \cdot D=2.5 \mathrm{~m}$.

This indicates that, for higher heat release rate per unit area values, not all fuel might be burnt yet when it reaches the ceiling and the fuel partly burns under the ceiling in the smoke layer (around stoichiometric mixture fraction). This gives rise to expansion phenomena, but it also implies a reduction of the buoyancy in the vertical flames and plume and thus a reduction of the smoke upward momentum. The higher the heat release rate, the more pronounced this effect will be, which might explain the less steep slope at the higher heat release rates. 


\section{Influence of ceiling height}

The range of car park ceiling heights is relatively small in practice. Figure 4 reveals that the required inlet velocity increases with increasing ceiling height. We find a 0.27 power law dependence of the critical ventilation velocity on the car park height:

$v_{c r} \propto h^{0.27}$, for the range of $h$ studied.
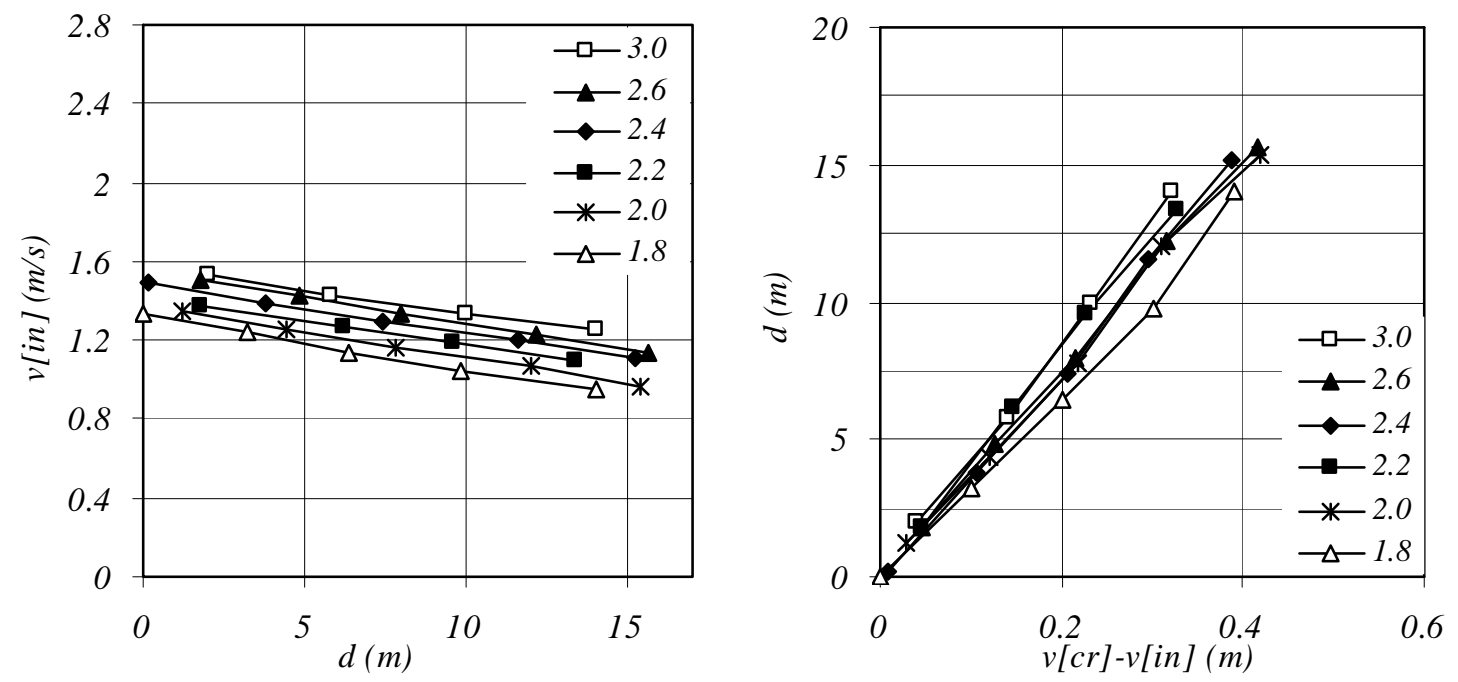

Fig. 4. Values of $v_{\text {in }}$ and $d$ (left) and $d$ as function of $\left(v_{c r}-v_{i n}\right)$ (right) for different heights $h$ (m).

Note that, at first sight, this is opposite to what is reported Eq. 3 above, from [3], as $Q^{*}<0.2$. However, as mentioned, Heskestad's correlation [10] yields a mean flame length estimate $l_{F}=2.5 \mathrm{~m}$ (Eq. 9). This clearly corresponds to a situation where the 'persistent flame region' reaches the ceiling. In [3], this corresponds to the situation above the threshold value, so that the second formula of Eq. 3 must be considered. Thus, the only difference is that we observe a 0.27 power law dependence, rather than a square root dependence.

Physically, the increase in critical ventilation velocity with car park height can be explained from the fact that an increase in car park height implies that the smoke plume contains more upward momentum due to buoyancy and higher ventilation velocities are required.

The value of the coefficient $a$ in Eq. 4 is practically independent of the car park height (Fig. 4, right):

$a \approx 39 \mathrm{~s}$. 


\section{Influence of car park width}

Figure 5 reveals that the influence of the car park width is small, but visible. A small decrease of $v_{c r}$ with increasing car park width $w$ is observed:

$v_{c r} \propto w^{-0.1}$
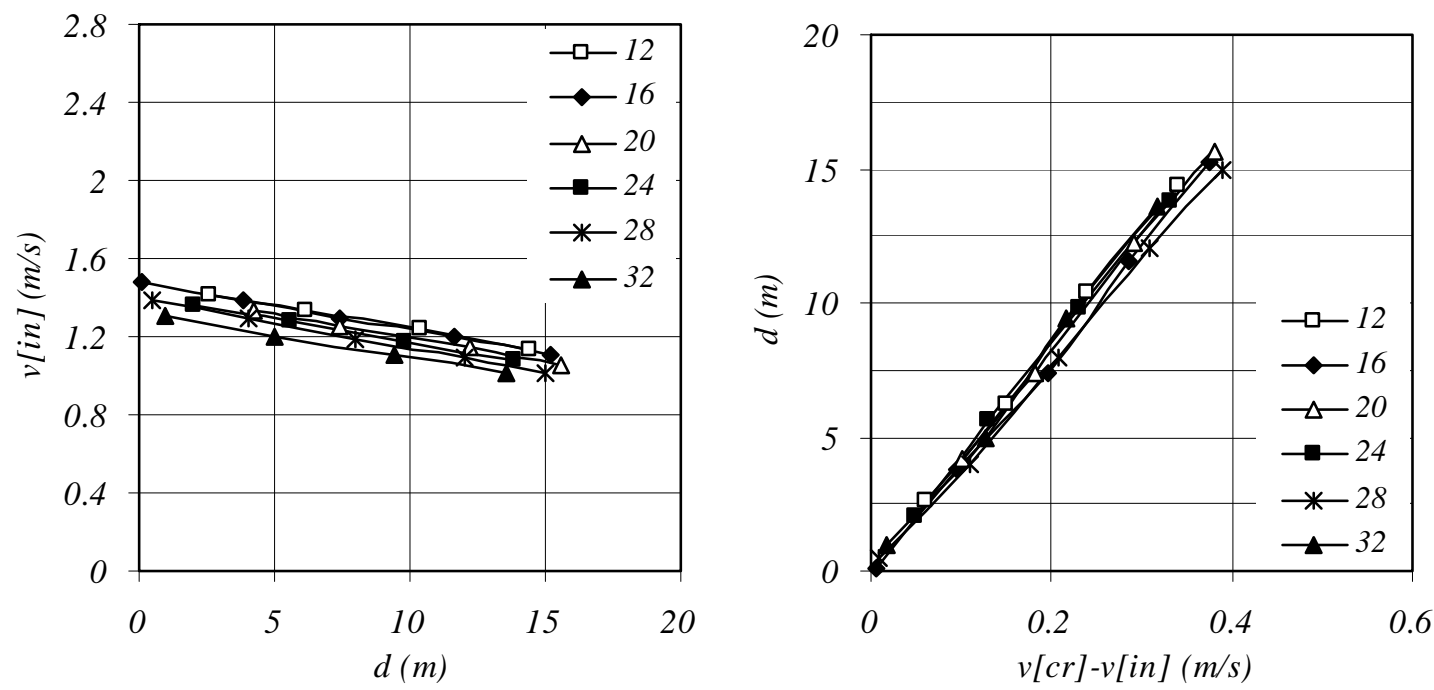

Fig. 5. Values of $v_{i n}$ and $d$ (left) and $d$ as function of $\left(v_{c r}-v_{i n}\right)$ (right) for different widths $w(\mathrm{~m})$.

The coefficient in Eq. 4 is independent of the car park width $w$ :

$a \approx 41 \mathrm{~s}$,

\section{Summary of the parameter study}

The results for the critical ventilation velocity can be summarized as:

$v_{c r}=0.196 \cdot \dot{q}_{c}^{, 0.28} A_{F}^{0.2} h^{0.27} w^{-0.1}$, for the range of configurations studied.

Thus, there are similarities and differences with Eq. 3:

- The increase of $v_{c r}$ with increasing $A_{F}$ obeys a one-fifth power, rather than a one-third power law dependence; note that, in [3], only one fire source area has been studied.

- The increase of $v_{c r}$ with increasing $\dot{q}_{c}^{\prime \prime}$ is confirmed, but no threshold value is observed here. This relation follows a 0.28 power law.

- A slight decrease of $v_{c r}$ with increasing car park width is observed.

- We only observe an increase in $v_{c r}$ with increasing car park height for the range of heights and configurations studied.

Recall that Eq. 14 refers to velocities at the inlet of the car park, not directly to extraction velocities. The possible differences between these velocities are discussed next. 
The summary of the results for the coefficient in Eq. 4, relating the backlayering distance to the difference between the critical ventilation velocity and the actually applied incoming air velocity, reads:

$$
a=111 \dot{q}_{c}^{,-0.2}
$$

where $a$ is expressed in seconds. It is interesting to note that $a$ is essentially independent of the car park width, car park height and fire source area. Clearly, this expression has only been validated for the range of parameter values as reported above. At the value $\dot{q}_{c}^{\prime \prime}=192 \mathrm{~kW} / \mathrm{m}^{2}, a$ becomes equal to $38.8 \mathrm{~s}$, a value in line with Eq. 6, 11 and 13.

\section{DIFFERENCE BETWEEN INLET AND OUTLET VELOCITIES}

Figure 6 summarizes the imposed outlet velocities and the corresponding inlet velocities in the FDS results for the basic configuration (with variable $\dot{q}_{c}^{\prime \prime}$ ). Clearly, the extraction velocity is higher than the inlet velocity. The difference can be substantial and increases as the convective HRR increases. This is a very important issue, as it is tempting to design the smoke control system, in particular the ventilation flow rates, based on 'cold conditions'. Indeed, such circumstances are easier to control in situ, by means of cold smoke tests. However, when a fire takes place, the hot smoke gas density at the location of the extraction fans will be lower than the incoming air density. Moreover, fans typically extract, to first order, constant volume flow rates, rather than constant mass flow rates (at constant rpm). Consequently, lower mass flow rates are extracted as the fire HRR increases. Thus, if the extraction volume flow rate is kept constant, the difference between actually extracted mass flow rate and design mass flow rate may be substantial.

As quantitative example, consider the configuration with 5MW convective HRR ( $\dot{q}_{c}^{\prime \prime}=192 \mathrm{~kW} / \mathrm{m}^{2}$ ), allowing $10 \mathrm{~m}$ of smoke backlayering. Figure 6 reveals that the inlet velocity must be $v_{\text {in }}=1.23 \mathrm{~m} / \mathrm{s}$. This value can also be obtained with Eq. 14 and 15 . It corresponds to a volumetric flow rate of $1.23 \mathrm{~m} / \mathrm{s} \mathrm{x} 16 \mathrm{~m} \mathrm{x}$ $2.4 \mathrm{~m}=170035 \mathrm{~m}^{3} / \mathrm{h}$. However, as seen in Fig. 6 , as the fan typically works in the smoke region, the required outlet velocity is $v_{\text {out }}=1.42 \mathrm{~m} / \mathrm{s}$, corresponding to the significantly higher extraction volume flow rate of $196522 \mathrm{~m}^{3} / \mathrm{h}$.

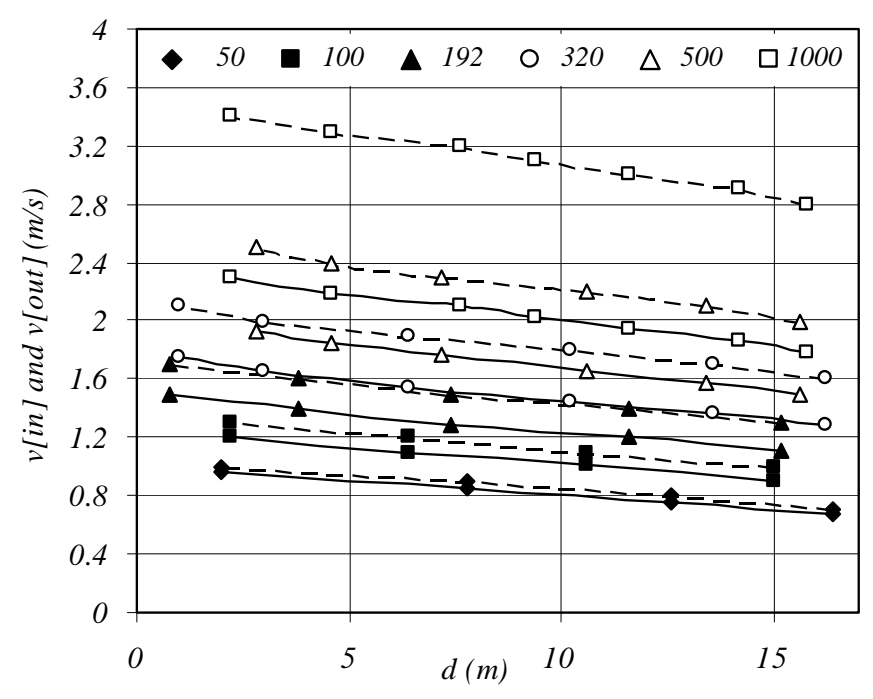

Fig. 6. Inlet (solid line) and outlet (dashed line) velocities for different $\dot{q}_{c}^{\prime \prime}\left(\mathrm{kW} / \mathrm{m}^{2}\right)$ values. 
Instead of using the CFD results directly, an estimate for the difference between inlet and outlet velocities can be determined from conservation of mass, ideal gas law and energy balance, assuming homogeneous temperature in the outlet plane:

$v_{\text {in }} \cdot \rho_{\text {in }}=v_{\text {out }} \cdot \rho_{\text {out }}$

$\frac{\rho_{\text {in }}}{\rho_{\text {out }}}=\frac{T_{\text {out }}}{T_{\text {in }}}=\frac{T_{\text {in }}+\Delta T}{T_{\text {in }}}$

$\dot{Q}_{c}=\Delta T \cdot \rho_{\text {in }} \cdot v_{\text {in }} \cdot A_{c s} \cdot c_{i n}$

Combination of Eq. 16-18, with $c_{\text {in }}=1 \mathrm{~kJ} /(\mathrm{kg} \cdot \mathrm{K})$, leads to the relation between inlet and outlet velocity:

$v_{\text {out }}=v_{\text {in }}+\frac{\dot{q}_{c}^{\prime \prime} \cdot A_{F}}{\rho_{\text {in }} \cdot w \cdot h \cdot T_{\text {in }}}$

For the quantitative example mentioned, this leads to $v_{\text {out }}=1.60 \mathrm{~m} / \mathrm{s}$, corresponding to an extraction volume flow rate of $221184 \mathrm{~m}^{3} / \mathrm{h}$. This value is higher than that obtained in FDS, so that application of Eq. 19 is a conservative way of designing the extraction volume flow rate. The difference between the value, calculated with Eq. 19, and the value, obtained in FDS, is due to the theoretical assumption that the temperature in the outlet plane is homogeneous. This is not the case, as observed in FDS.

\section{CONCLUSIONS}

We analysed results from a large number of CFD simulations of fires in large closed car parks. We revealed a linear relation between the smoke backlayering distance from the fire source and the difference between the critical ventilation velocity (for which no backlayering occurs) and the actual inlet air ventilation velocity (Eq. 4). The coefficient (Eq. 15) in this expression

- $\quad$ is independent of the fire source area $A_{F}$,

- is inversely proportional to the one-fifth power of the convective HRR per unit area,

- is independent of the car park height,

- is independent of the car park width.

We also illustrated and explained the following observations for critical ventilation values (Eq. 14):

- increase with fire source area (one-fifth power),

- increase with convective HRR per unit area (0.28 power),

- increase with car park height (0.27 power),

- modest decrease with increasing car park width (-0.1 power).

The obtained values are limited to the range of configurations studied.

Finally, we pointed out that the differences between inlet air ventilation velocities and smoke extraction velocities can be substantial. This is important: if smoke control systems are designed and controlled for 'cold conditions' (i.e. corresponding to inlet air velocities), the actually extracted mass flow rates in case of fire may be too low. 


\section{REFERENCES}

[1] Chow, W.K., (1998) On safety systems for underground car parks, Tunnelling and Underground Space Technology 13(3): 281-287, http://dx.doi.org/10.1016/S0886-7798(98)00060-1

[2] Beard, A., Carvel, R., The handbook of tunnel fire safety, Thomas Telford Services Ltd, London, 2005

[3] Wu, Y., Bakar, M.Z.A., (2000) Control of smoke flow in tunnel fires using longitudinal ventilation systems - a study of the critical velocity, Fire Safety Journal 35: 363-390, http://dx.doi.org/10.1016/S0379-7112(00)00031-X

[4] NBN S21-208-2, Fire protection inside buildings - Design of smoke and heat exhaust ventilation systems (SHEVS) for indoor car parks, 2007

[5] BS 7346-7, Code of practice on functional recommendations and calculation methods for smoke and heat control systems for covered car parks, 2006

[6] McGrattan Kevin, Fire Dynamics Simulator (version 4) Technical Reference Guide. National Institute of Standards and Technology, NIST Special Publication 1018, 2004

[7] Profil ARBED (centre de recherche - L), ULG (B), CTICM (F), TNO (NL), LABEIN (SP), Development of design rules for steel structures subjected to natural fires in closed car parks, 1997

[8] Pope, S.B., Turbulent Flows, Cambridge University Press, Cambridge, 2000.

[9] Merci, B., Van Maele, K., (in press) Numerical Simulations of Full Scale Enclosure Fires in a Small Compartment with Natural Roof Ventilation, Fire Safety Journal.

[10] Heskestad, G., "Fire Plume air Entrainment According to Two Competing Assumptions", Proceedings of the twenty-first International Symposium on Combustion, The Combustion Institute, 1986, pp. 111-120. 
